\title{
The Organization and Economics of Sports Mega-Events
}

Summer in even-numbered years means the commencement of a season of large-scale sporting events, such as the Olympics, the FIFA World Cup or the UEFA European Championship. A growing body of literature challenges the PR campaigns of these so-called "mega-events" and questions the economic rationale of hosting these extremely expensive spectacles. In light of the imminent commencement of the UEFA Championship in France and the Olympics in Rio, as well as the prospective bids of Rome and Paris for the 2024 Olympics, it is an opportune time to shed some light on the benefits and costs of hosting a mega-event. Much of the following research is drawn from my book Circus Maximus: The Economic Gamble Behind Hosting the Olympics and the World Cup.

Mega-events are far from the economic engines they are touted to be. It is almost a universal experience that these events engender more short-run costs than short-run revenues, and that the expected long-run gains in tourism, trade and foreign investment are not forthcoming. Depending on the event and the host city or country, the actual economic outcome can range from significantly negative, to neutral, to modestly positive. The modestly positive experiences, however, are few and far between and necessitate special circumstances.

One positive experience was Barcelona in 1992, which has become the poster child of success for cities hosting the Olympic Games. Each new host city studies and seeks to emulate the Barcelona experience. In many ways, the Barcelona case does indeed represent how to do it right, and there is good reason for other cities to try to learn from it. In other ways, however, the circumstances in Barcelona were unique and will not be easy for other cities to replicate.

Franco ruled Spain from 1939 until his death in 1975. The Catalonian region, where Barcelona is located, was relatively neglected during this period. Development in Barcelona was characterized by real estate speculation and inadequate investment in infrastructure, and little thought was given to urban design. Despite Barcelona's desirable climate, location on the Mediterranean Sea, rich architectural heritage and interesting culture, the city was well down the list of European tourist destinations and business centers.

With the end of Francoism, the city anxiously anticipated a new opportunity to reshape its development. A positive spirit of cooperation between capital and labor and among the municipal, regional and national governments fostered a proactive approach. In 1976 the city produced the General Metropolitan Plan (PGM), which established a new spatial framework for the city. A significant part of this framework entailed opening the city to the sea. This involved relocating rail lines that separated downtown from the sea and placing a roadway below grade at the bottom of the famous street, Las Ramblas. It also meant that an area of mostly abandoned warehouses and factories would be razed and become the eventual site of the Olympic Village, to be converted to residential housing after the games. Other parts of the plan related to improving the road network around the city, extending the metro system, redesigning the airport, renovating public spaces and museums, and modernizing the sewage system.

Thus, an early plan for urban redevelopment was formulated by 1976 and then elaborated in the following years. It was not until 1986 that the IOC selected Barcelona to host the 1992 Games. In 1983 city planners put out a preliminary report on the feasibility of hosting the Olympics and concluded that the refurbishment of the 1936 stadium in 
Montjuic (which became the Olympic Stadium) and the construction of the Sports Palace and swimming facility would be undertaken whether or not the city was selected to host the games. Of the 37 sports facilities ultimately used during the 1992 Olympics, 27 were already built and another five were under construction at the time Spain was selected to host the games in 1986. Thus, a central feature of the Barcelona experience is that the plan preceded the Games, and hence the Games were put at the service of the preexisting plan, rather than the typical pattern of the city development plan being put at the service of the Games.

The general experience, however, is otherwise. The Summer Olympics and the World Cup generate under $\$ 5$ billion in revenue for the host, while the Winter Olympics generate around $\$ 3$ billion. Thus, when London spends $\$ 18$ billion, Beijing spends $\$ 44$ billion or Sochi spends $\$ 51$ billion, the possibility for a surplus vanishes. (Note that while reports of surpluses frequently appear in the press, this is invariably because infrastructure and most venue costs or public subsidies via tax exemptions are excluded from the accounting.)

While it is an advantage to be able to use existing facilities, as the United States was able to for the 1994 World Cup, Germany was able to for the 2006 World Cup and France can soon do for the European Championship, there are other direct and indirect costs that make it difficult for the host to realize economic gains. Special transportation and hospitality arrangements have to be made for FIFA and IOC executives, security has to be provided, "back of house" overlay for the sports venues is required, billboards and signage space must be cleared, tax preferences must be granted, some facilities require renovation, and so on. Due to expectations of higher prices, heavy traffic, congestion and the possibility of security incidents, traditional tourists may stay away in droves, yielding lower hotel occupancy rates. In fact, the econometric scholarship on the economic impact of both the 1994 and 2006 World Cups suggests either stagnant or falling employment and income in host cities.

UEFA's Euro 2016 football tournament will be hosted by France. French football fans may derive psychic income from having this competition in their own country. But depending on the amount of new construction and the operating costs, based on past experience, we can expect the economic impact to be either neutral or negative. The Euro 2012 tournament was hosted jointly by Poland and Ukraine. The total cost was \$39 billion. In Poland, three of the construction companies with contracts for the competition went bankrupt. The public debt in the Ukraine from hosting was estimated at between $\$ 6$ billion and \$8 billion. The financially ruinous 2004 Olympic Games in Athens left a debt of $\$ 4$ billion.

UEFA's 2020 tournament, to mark the 60th anniversary of the first event, will be spread across venues throughout Europe. The good news here is that the costs of hosting will be shared by several countries. The bad news is that the hydrocarbon footprint of the tournament will be enlarged and that administrative and security costs will be experienced by several countries.

International sporting competitions are fun and, if done properly, hold the promise of increasing understanding among different peoples and cultures in our strife-ridden world. Yet, if done as spectacle, with concentration on grandiosity and ostentation, these mega-events inflict unnecessary debt on their hosts and undermine sustainability concerns. Having European countries share the burden, as will be done in the 2020 European Championship, may ameliorate some of the financial costs on individual countries,

Andrew Zimbalist, Smith College, Northampton, MA, USA. but it does not address the fundamental problems of waste and poor planning. 